\title{
Kinetic and Thermodynamic Spectrophotometric Technique to Estimate Gabapentin in Pharmaceutical Formulations using Ninhydrin
}

\author{
Farhan Ahmed Siddiquii ${ }^{*}$, Nawab Sher ${ }^{2}$, Nighat Shafi ${ }^{1}$, Hina Shamshad ${ }^{3}$ and Arif Zubair ${ }^{4}$
}

\begin{abstract}
Background: Simple and sensitive spectrophotometric method is described based on the reaction of drug (gabapentin) with ninhydrin in pure form and in pharmaceutical preparations.

Methods: Complex formed during this reaction is measured at $575 \mathrm{~nm}$ as a function of time. Kinetic study involve initial-rate, rate-constant and fixed-time (80 minutes) procedures to determine the concentration of the drug.

Results: Drug was studied in the concentration range of $10-30 \mu \mathrm{gmL}^{-1}$ showing correlation coefficient 0.9997 , 0.9970 and 0.9990 for initial rate, rate constant and fixed time respectively. Limit of detection (LOD) and limit of quantification (LOQ) was found to be 0.13 and 0.04 nana grams respectively. The variables affecting the reactions were optimized and the developed method was validated according to $\mathrm{ICH}$ guidelines.

Conclusion: The proposed method has been efficiently applied to the estimation of gabapentin in pharmaceutical formulation with first-class recovery (98.3-101.4\%). Thermodynamic parameters were studied i.e., association constants and standard free energy changes were determined by Benesi-Hildebrand equation while, Gibbs free energy change for the complex was also estimated.
\end{abstract}

Keywords: Spectrophotometric determination; gabapentin; ninhydrin and charge transfer complex

\section{Background}

The new anti-convulsant drug gabapentin (1(aminomethyl)cyclo-hexaneacetic acid) is a GABA analogue. It was originally developed for the treatment of epilepsy, and currently, gabapentin is widely used to relieve pain, especially neuropathic pain, it is indicated in the treatment of epilepsy and neuropathic pain, also in the treatment of bipolar disorder and may be effective in reducing pain and spasticity in multiple sclerosis. Gabapentin is a $\gamma$-aminobutyric acid (GABA) analogue that does not bind to GABA receptors or alter GABA metabolism in the brain (Goldlust et al. 1995). Its action is attributed to the irreversible inhibition of the enzyme GABA-transaminase, thus preventing the physiological degradation of GABA in the brain (Ouellet et al. 2001). Analytical methods reported for its determination

\footnotetext{
* Correspondence: farhanchemist@gmail.com

${ }^{1}$ Faculty of Pharmacy, Federal Urdu University Arts, Science and Technology, Karachi 75300, Pakistan

Full list of author information is available at the end of the article
}

consist of high-performance liquid chromatography (HPLC) (Jiang \& Li 1999; Tang et al. 1999; Chollet et al. 2000; Ifa et al. 2001; Ratnaraj \& Patsalos 1998; Wad \& Kramer 1998), spectrofluorimetry (Belal et al. 2002; Hassan et al. 2001), gas chromatography-mass spectrometry (GC-MS) (Kushnir et al. 1999; Van Lentea \& Gatautis 1998), capillary electrophoresis (Rada et al. 1998) and spectrophotometry applying Hantzsch reaction (al-Zehouri et al. 2001). So far, no traces of any attempts have been found for determination of gabapentin by colorimetric method and the literature is still starving for such analytical procedures. There are number of methods for determination of gabapentin in literature (Manera et al. 2009; Lin et al. 2004; Jia et al. 2012; Ribeiro et al. 2007; Abdulrahman \& Basavaiah 2011; Abdulrahman \& Basavaiah 2012; Jalali et al. 2007; Hegde et al. 2009; Patel et al. 2011; Siddiqui et al. 2010).

Reactions with ninhydrin (NIN) has been widely used to analyze and characterize amino acids, thiophen and proteins as well as numerous other NIN positive 
compounds in biomedical, clinical, food, forensic, histochemical, microbiological, nutritional and plant studies (Friedman 2004). It has been extensively used in the determination of the compounds of pharmaceutical importance applied to their kinetic studies (Rahman \& Azmi 2001a; Campins-Falco et al. 1996; Arayne et al. 2008). Present study describes a direct, sensitive and precise spectrophotometric method simpler than the existing UV and HPLC methods that is free from such experimental variables as extraction step for the determination of gabapentin in reference material and pharmaceutical formulations by means of developing charge transfer complex with NIN.

No interference was observed in the assay of gabapentin from common excipients in levels found in pharmaceutical formulations. The method rely on the use of simple and inexpensive technique but give out sensitivity analogous to that procured by sophisticated and expensive techniques such as HPLC, and are validated as per ICH recommendations (ICH Topic Q2(R1) 2005). The kinetic approach for determining gabapentin in commercial dosage form, using NIN as a reagent, confer simplicity and rapidity as the procedure simply require heating and cooling of the reaction mixture. During this study the reaction conditions and application of the methods for determination of gabapentin in pharmaceutical formulations have been established, in addition, the association constant, stoichiometric ratio of reactants and the standard free energy changes $\left(\Delta G^{\circ}\right)$ were determined.

Our present study suggests kinetic and thermodynamic spectrophotometric procedure for the determination of gabapentin in pharmaceutical formulations. The methods are based on the reaction of primary amino group of gabapentin with NIN.

\section{Experimental \\ Apparatus}

Shimadzu 1601 double beam UV-visible spectrophotometer possessing a fixed slit width $(2 \mathrm{~nm})$ with quartz cells of $10 \mathrm{~mm}$ path length connected to a PIV computer loaded with Shimadzu UVPC version 3.9 software were used to record the absorption spectra.

\section{Materials and reagents}

All reagents were of analytical grade. Gabapentin pure drug was obtained from Godecke AG, Darmstadt, Germany under license of Park-Davis (Pvt.) Ltd. Karachi, Pakistan. Gabin ${ }^{\circ}$ capsules 200 mg (PharmEvo Pharmaceutical Company (Pvt.) Ltd., Karachi, Pakistan), Gaba ${ }^{\circ}$ capsules $100 \mathrm{mg}$ (Nabi Qasim Pharmaceuticals (Pvt) Ltd., Karachi, Pakistan), Gabaplus ${ }^{\circ}$ capsules 100 mg (Platinum Pharma (Pvt.) Ltd., Karachi, Pakistan) and Neupentin ${ }^{\circ}$ capsules 400 mg (Highnoon Pharma (Pvt.)
Ltd., Karachi, Pakistan) were purchased from the market. Ninhydrin was purchased from Merck Schuchardt OHG, Darmstadt, Germany. HPLC grade methanol was from fisher scientific UK.

\section{General procedure}

\section{Preparation of standard stock solutions}

Solution of $0.1 \mathrm{mgmL}^{-1}$ gabapentin was prepared in water by dissolving $10 \mathrm{mg}$ of gabapentin in $100 \mathrm{~mL}$ of purified water and stored in a cool $\left(<25^{\circ} \mathrm{C}\right)$ and dark place. Ninhydrin reagent was $2 \mathrm{mgmL}^{-1}$ in methanol and was prepared fresh daily.

\section{Method}

Aliquots of $1 \mathrm{~mL}$ of stock solution corresponding to 100 $\mu \mathrm{gmL}^{-1}$ of gabapentin were transferred into heating tubes. $2 \mathrm{~mL}$ of $1 \%$ NIN solution was added and heated on boiling water bath for 2 hours, after cooling the mixture was transferred into $25 \mathrm{~mL}$ volumetric flask and diluted to volume with distilled water. Increase in absorbance at $575 \mathrm{~nm}$ was recorded as a function of time against the reagent blank at room temperature (spectra 1). The initial rate of reaction at different concentrations was calculated from the initial slope of absorbance time curve. The calibration curves were constructed by plotting logarithm of initial-rate of reaction versus logarithm of molar concentration, rateconstant versus final concentration and absorbance measured at a fixed-time versus final concentration of gabapentin.

\section{Procedures for pharmaceuticals formulation}

Twenty capsules of each formulation were weighed and powdered. The powder equivalent to $10 \mathrm{mg}$ of gabapentin was dissolved in $100 \mathrm{~mL}$ of water to give $0.1 \mathrm{mg} \mathrm{mL}^{-1}$ of gabapentin. The procedure was continued as described under general procedures.

\section{Stoichiometric study}

Job's method of continuous variation (Rose 1964) was employed. Master equimolar solution of gabapentin was prepared in water whereas NIN was prepared in methanol and made up to volume with the same solvent. A series of $10 \mathrm{~mL}$ portions of master solution of gabapentin with NIN was made up comprising different complementary proportions $(0: 10,1: 9,2: 8 \ldots . .9: 1)$ in 10 $\mathrm{mL}$ calibrated flasks. The absorbance of the resulting solutions were measured at the wavelength of maximum absorption after the appropriate time against reagent blanks treated similarly.

\section{Interference from excipients}

Samples were prepared by mixing $50 \mathrm{mg}$ of gabapentin with various amounts of common excipients such as 
glucose, lactose, talc powder, magnesium stearate, pyrrolidone, HPMC (hydroxypropylmethylcellulose) and starch. The procedure was continued as described under general procedures.

\section{Results and discussion}

Gabapentin exhibits a very low UV absorption, with $A_{1 \mathrm{~cm}}^{1 \%}$ at $276 \mathrm{~nm}=6.5$ (Abdellatef \& Khalil 2003) and as a result poor sensitivity will be achieved by conventional UV spectrophotometric methods. There was a critical need to develop a spectrophotometric method that could quantitate gabapentin in pharmaceutical formulations.

\section{Reaction with Ninhydrin (NIN)}

Ninhydrin reagent is used for the determination of an aliphatic primary amine or an amino acid group (Friedman 2004; Rahman \& Azmi 2001a; Campins-Falco et al. 1996; Arayne et al. 2008; Rahman \& Azmi 2001b; Nobrega Jde et al. 1994; Molnar-Perl \& Pinter-Szakacs 1989). The presence of an aromatic ring exhibits the response; the exhibition increases if the amino group is nearer to the ring. The end product of NIN reaction with amino acid (Ruhemanns purple) give best color in methanol, however water can be used as good option in case when extraction of the active molecule is compromised. The reaction mixture is heated for a short while and is measured at maximum wavelength $568 \mathrm{~nm}$ which is dependent on solvent system and reaction condition (Görög 1995).

Gabapentin interacts with NIN in pure methanol via oxidative deamination of the primary amino group followed by the condensation of the reduced NIN to form the purple colored reaction complex with $\lambda_{\max }$ at $575 \mathrm{~nm}$ (Figures 1 and 2).

Gabapentin was found to be competent of reacting with NIN only at higher temperatures. Maximum color was obtained by heating on a water bath at $70 \pm 5^{\circ} \mathrm{C}$ for 80 minutes. Prolonged heating decreased the chromogenic intensity, so the reaction time should be controlled. Different solvents such as water, ethanol, methanol, isopropanol, and acetonitrile have been tried, but the best results were obtained with methanol.

\section{Optimization of reaction}

The reaction between gabapentin and ninhydrin in methanol resulted in the formation of blue colored complex. At $70^{\circ} \mathrm{C}$, the intensity of color increased with time and became stable after 80 minutes.

\section{Kinetic studies}

Initial rate method In order to study the kinetic parameters of the proposed reactions, the initial rate of the reaction was determined by using time curve (from the measurement of the slope of the initial tangent to the absorbance). Concentration of NIN was kept constant and the reaction was studied at different concentrations of gabapentin to establish the order of reaction with respect to gabapentin. For each run, a plot of $\log A_{¥} / A_{¥}-$ $A_{t}$ versus time was a straight line indicating a first order reaction. The first order rate constant was also estimated from the slopes of the above plot.

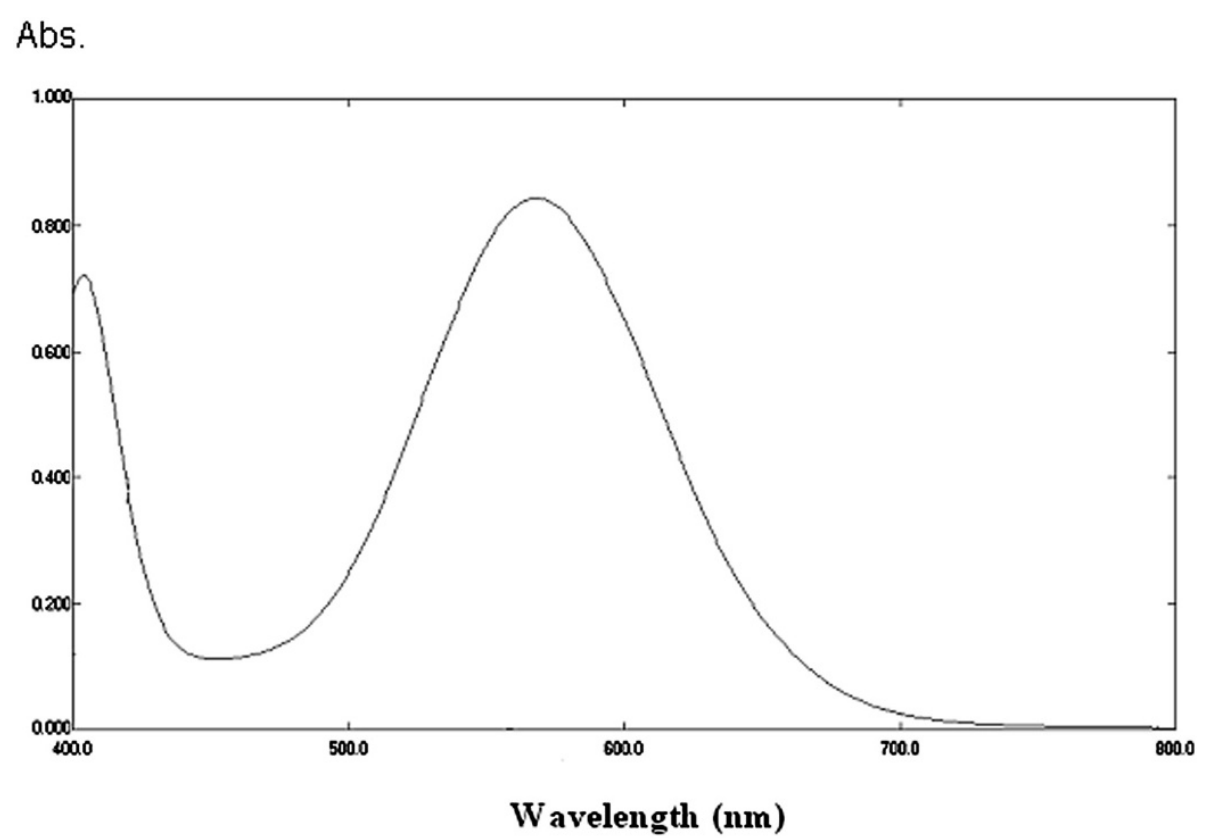

Figure 1 Absorption spectra of the reaction products of gabapentin with NIN. 


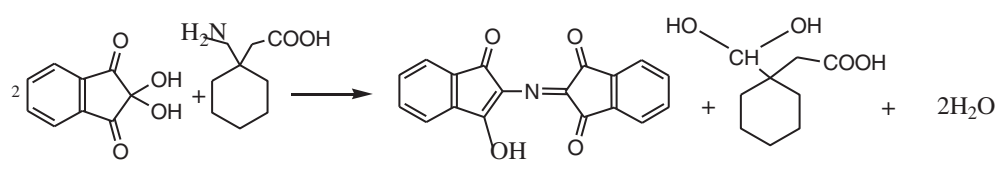

Figure 2 Suggested reaction pathway between gabapentin and NIN.

Similarly to establish order of reaction with respect to NIN, all subsequent investigations were conducted with fixed concentration of gabapentin and varied concentrations of NIN. The first order kinetics was also confirmed by plot of $\log A_{¥} / A_{¥}-A_{t}$ versus time. The initial rate of reaction under pseudo-first order conditions would obey the following equation:

$$
\text { Rate }=\mathrm{dA} / \mathrm{dt}=\mathrm{k}^{\prime} \mathrm{C}^{\mathrm{n}}
$$

Where, " $k$ "' is the pseudo-first order rate constant, " $C$ " is the concentration of gabapentin, " $n$ " is the order of reaction. The above equation may be written in the logarithmic form as,

$$
\text { Log rate }=\log \mathrm{k}^{\prime}+\mathrm{n} \log \mathrm{C}
$$

Linear regression analysis was used to calculate slope, intercept and correlation coefficient (Table 1). The regression of $\log$ rate versus $\log C$ gave a linear regression equation,

$$
\text { Log rate }=\log \mathrm{k}^{\prime}+0.01018 \log \mathrm{C}
$$

The value of " $n$ " in the regression equation also indicated the first order reaction with respect to gabapentin concentration. The calibration curve constructed in the range of $10-30 \mu \mathrm{gmL}^{-1}$ (absorbance of different concentrations of gabapentin versus time) showed a linear relationship.

Rate-constant method The rate constant values analogous to different concentrations of gabapentin were calculated by plotting the slopes of $\log A_{¥} / A_{¥}-A_{t}$ versus time under pseudo-first order conditions (Table 2). The calibration graph was constructed by plotting rate constant against the concentration of gabapentin, and a linear response in the concentration range of $10-30 \mu \mathrm{gmL}^{-1}$ were observed. Consequent data is presented in Table 2.

Table 1 Statistical and regression data of proposed method

\begin{tabular}{cccc}
\hline & Initial Rate & Rate Constant & Fixed Time \\
\hline Intercept & 0.0021 & -0.22284 & -0.0028 \\
Slop & 0.01018 & 0.014626 & 0.0129 \\
$r^{2}$ & 0.9994 & 0.9990 & 0.9999 \\
Correlation coefficient $(\mathbf{r})$ & 0.9997 & 0.9970 & 0.9990 \\
\hline
\end{tabular}

Fixed time method A single concentration of gabapentin was monitored at $575 \mathrm{~nm}$ against reagent blank at a pre selected fixed time. A plot of absorbance versus initial concentration of gabapentin was calibrated at fixed time (20, 40, 60 and 80 minutes). Regression equations were developed keeping working standards in view and important analytical parameters have been calculated (Table 3) which were found to be in acceptable limits for correlation coefficient, intercept and slope at all fixed time. It is hence suggested that any fixed time can be used for assay of gabapentin.

The high values of correlation coefficients resulting from regression equations demonstrate reliable linearity of the methods. The values of slopes of the regression equations of the proposed methods indicate good sensitivity. The small values of the standard deviation address the precision of the calibration data points around the line of regressions for all the proposed procedures. Independent repeatability studies were performed of the proposed methods with five replicates for each method (Table 4). The obtained data shows that the methods can be applied to dosage formulations with accuracy and precision (Table 5).

\section{Stoichiometry of the reaction}

On observing the molar ratio of the gabapentin with NIN using Job's method of continuous variation (Rose 1964), it was found to be $1: 2$ for NIN.

\section{Thermodynamic studies}

Association constants and standard free energy changes

The association constants were determined for the interaction of gabapentin with NIN using Benesi-Hildebrand equation (Benesi \& Hidelbrand 1949) was $1.418 \times 10^{3}$.

$$
\frac{C a}{A}=\frac{1}{\varepsilon}+\frac{1}{K c \cdot \varepsilon} \cdot \frac{1}{C b} .
$$

Table 2 Method of rate constant

\begin{tabular}{cc}
\hline Concentration $\boldsymbol{\mu g m L}^{-1}$ & $\begin{array}{c}\text { Calculated Value of Rate Const } \\
\text { (slope) } \text { Min }^{-1}\end{array}$ \\
\hline 10 & 0.0147 \\
14 & 0.0146 \\
18 & 0.0146 \\
20 & 0.0146 \\
30 & 0.01463 \\
\hline
\end{tabular}


Table 3 Regression characteristics of gabapentin concentration at different time interval

\begin{tabular}{ccccc}
\hline (Fixed Time) & $\mathbf{2 0}$ & $\mathbf{4 0}$ & $\mathbf{6 0}$ & $\mathbf{8 0}$ \\
\hline Intercept & -0.002 & -0.0022 & -0.0034 & -0.0036 \\
Slope & 0.0112 & 0.0124 & .0114 & 0.0115 \\
Correlation coefficient $(\mathbf{r})$ & 0.9990 & 0.9992 & 0.9998 & 0.9999 \\
\hline
\end{tabular}

where $C a$ and $C b$ are the concentrations of the acceptor and donor respectively, $A$ is the absorbance of the complex, $\varepsilon$ is the molar absorptivity of the complex and $K_{\mathrm{c}}$ is the association constant of the complex.

Straight line was obtained by plotting $C a$ versus $A$ and Gibbs Free energy change for the complex was calculated to be $(-4.947)$ by using equation as given below (Martin et al. 1969).

$$
\Delta G^{\circ}=-2.303 R T \log K_{C}
$$

Where $\Delta G^{\circ}$ is the free energy change of the complex $\left(\mathrm{kJ} \mathrm{mol}{ }^{-1}\right), R$ the gas constant $\left(1.987 \mathrm{cal} \mathrm{mol}^{-1} \mathrm{deg}^{-1}\right), T$ the temperature in Kelvin $\left(273+^{\circ} \mathrm{C}\right)$ and $K_{\mathrm{c}}$ is the association constant of drug-acceptor complexes $\left(1 \mathrm{~mol}^{-1}\right)$.

\section{Linearity, accuracy and precision}

Linearity, accuracy and precision were assessed for the method in the range of 10 to $30 \mu \mathrm{gmL}^{-1}$. Regression statistics were calculated for the colorimetric procedures and linear regression plots showed the directly proportional relationship of absorbance over Beer's law range given in Tables 1 and 4. The table also shows the results of the statistical analysis of the experimental data, such as the slopes, the intercepts, the Square of correlation coefficients obtained by the linear least-squares treatment of the results.

Five different concentrations of gabapentin were prepared, each solution was analyzed in five replicate to evaluate the accuracy and precision of the methods.. The mean Standard Deviation and\% relative standard deviation (\%RSD) as depicted in Table 4 were found to be in the acceptable range of $(0.0793-0.8376)$ and $(0.494-0.8317)$ respectively.

It was observed that at specific wavelength the absorption intensity was dependent upon the concentration of gabapentin. It was observed that Beer's law was followed in all cases with very small range of intercept values $(-0.0028$ to 0.0021$)$ and slopes ranged from $(0.01018$ to 0.0146) for the concentration ranges as described in Table 1. The correlation coefficient values were found to be in the range of $0.9970-0.9997$ using the least-square method.

\section{Specificity}

The interference of excipients, additives and other substances present in formulation and the affect of degradation products of gabapentane on the proposed method were experimentally observed. Ionization potential of the donor and the electron affinity of the acceptor are the two main parameters which influenced the energy of complex. The basic nature of gabapentin due to charge transfer is responsible for its specificity to the reaction. Hence a degradation product of gabapentin does not have specificity for the reaction as they lack the basicity. The percentage recoveries as shown in Table 6 confirmed that there was no interference from any excipient present in the formulation for the proposed method.

Limit of detection (LOD) and limit of quantification (LOQ) The theoretically determined values of LOD and LOQ for gabapentin with NIN were cross checked by actual analysis of these concentrations using proposed methods. LOD of gabapentin with NIN $0.04 \mu \mathrm{g} \mathrm{mL}$ while LOQ were $0.13 \mu \mathrm{g} \mathrm{mL} \mathrm{m}^{-1}$.

\section{Analysis of pharmaceutical dosage forms}

The determination of gabapentin in formulation was carried out using the proposed charge transfer spectrophometric method along with the reference

Table 4 Accuracy and precision of proposed method

\begin{tabular}{|c|c|c|c|c|c|c|}
\hline \multirow[b]{2}{*}{ Amount } & \multicolumn{2}{|c|}{ Initial Rate } & \multicolumn{2}{|c|}{ Rate Constant } & \multicolumn{2}{|c|}{ Fix Time } \\
\hline & Found & $\%$ Recover & Found & $\%$ Recover & Found & $\%$ Recover \\
\hline 10 & 10.05 & 100.5 & 9.96 & 9.96 & 10.1 & 101 \\
\hline 14 & 14.14 & 101 & 13.95 & 9.96 & 14.15 & 101 \\
\hline 18 & 18.22 & 101.22 & 18.17 & 10.09 & 17.98 & 99.8 \\
\hline 20 & 19.86 & 99.3 & 20.22 & 10.11 & 20.2 & 101 \\
\hline 30 & 30.41 & 101.36 & 29.85 & 9.98 & 30.17 & 100 \\
\hline Mean & & 100.6778 & & 10.01575 & & 100.70 \\
\hline STD & & 0.837361 & & 0.079303 & & 0.4987 \\
\hline RSD & & 0.831723 & & 0.791779 & & 0.494 \\
\hline
\end{tabular}

STD = Standard deviation, RSD = Relative standard deviation 
Table 5 Determination of gabapentin in pharmaceuticals formulations by proposed

\begin{tabular}{|c|c|c|c|c|c|c|c|c|}
\hline \multirow[b]{3}{*}{ Taken } & \multicolumn{2}{|c|}{ Ini. Rate } & \multicolumn{2}{|c|}{ Rate Constant } & \multicolumn{2}{|c|}{ Fix Time } & \multicolumn{2}{|c|}{ Reference method } \\
\hline & \multicolumn{8}{|c|}{ Gabaplus 100 mg cap (Platanium) } \\
\hline & Found & $\% \operatorname{Rec}$ & Found & $\% \operatorname{Rec}$ & Found & $\% \operatorname{Rec}$ & Found & $\% \operatorname{Rec}$ \\
\hline 100 & 100.78 & 100.78 & 99.38 & 99.38 & 101.30 & 101.3 & 99.2 & 99.2 \\
\hline 100 & 99.540 & 99.54 & 100.84 & 100.84 & 98.88 & 98.88 & 101.4 & 101.4 \\
\hline 100 & 101.230 & 101.23 & 98.41 & 98.41 & 99.40 & 99.4 & 100.66 & 100.66 \\
\hline 100 & 98.670 & 98.67 & 101.28 & 101.28 & 100.66 & 100.66 & 98.3 & 98.3 \\
\hline 100 & 100.230 & 100.23 & 99.63 & 99.63 & 99.30 & 99.3 & 100.7 & 100.7 \\
\hline Mean & 100.090 & 100.09 & 99.91 & 99.908 & 99.91 & 99.908 & 100.05 & 100.052 \\
\hline STD & 1.014 & 1.01417 & 1.16 & 1.15662 & 1.02 & 1.023191 & 1.27 & 1.26512 \\
\hline RSD & 1.013 & 1.013263 & 1.16 & 1.157685 & 1.024133 & 1.024133 & 1.264459 & 1.26446 \\
\hline T-Test & 0.72 & & 0.83 & & 0.94 & & & \\
\hline \multirow[t]{2}{*}{ F-Test } & 1.26 & & 1.39 & & 1.05 & & & \\
\hline & \multicolumn{8}{|c|}{ Gabin 200 mg cap (PharmEvo) } \\
\hline Taken & Found & $\% \operatorname{Rec}$ & Found & $\% \operatorname{Rec}$ & Found & $\% \operatorname{Rec}$ & Found & $\% \operatorname{Rec}$ \\
\hline 200 & 201.300 & 100.65 & 202.20 & 101.1 & 199.30 & 99.65 & 202.2 & 101.1 \\
\hline 200 & 200.680 & 100.34 & 199.30 & 99.65 & 201.50 & 100.75 & 197.9 & 98.95 \\
\hline 200 & 198.950 & 99.475 & 198.80 & 99.4 & 200.80 & 100.4 & 198.6 & 99.3 \\
\hline 200 & 199.200 & 99.6 & 201.30 & 100.65 & 201.40 & 100.7 & 200.6 & 100.3 \\
\hline 200 & 198.300 & 99.15 & 200.80 & 100.4 & 199.40 & 99.7 & 200.6 & 100.3 \\
\hline Mean & 199.686 & 99.843 & 200.48 & 100.24 & 200.48 & 100.24 & 199.98 & 99.99 \\
\hline STD & 1.254 & 0.627092 & 1.41 & 0.704805 & 1.07 & 0.533151 & 1.73 & 0.86342 \\
\hline RSD & 0.628 & 0.628079 & 0.70 & 0.703117 & 0.531875 & 0.531875 & 0.86351 & 0.86351 \\
\hline T-Test & 0.68 & & 0.94 & & 0.73 & & & \\
\hline \multirow[t]{2}{*}{ F-Test } & 1.25 & & 1.48 & & 1.17 & & & \\
\hline & \multicolumn{8}{|c|}{ Neupentin 400 mg cap (Highnoon) } \\
\hline Taken & Found & $\% \operatorname{Rec}$ & Found & $\% \operatorname{Rec}$ & Found & $\% \operatorname{Rec}$ & Found & $\% \operatorname{Rec}$ \\
\hline 400 & 400.800 & 100.2 & 398.40 & 99.6 & 398.50 & 99.625 & 402.87 & 100.718 \\
\hline 400 & 402.100 & 100.525 & 397.50 & 99.375 & 401.20 & 100.3 & 400.96 & 100.24 \\
\hline 400 & 398.600 & 99.65 & 401.50 & 100.375 & 400.90 & 100.225 & 397.5 & 99.375 \\
\hline 400 & 399.400 & 99.85 & 402.80 & 100.7 & 401.20 & 100.3 & 398.2 & 99.55 \\
\hline 400 & 398.200 & 99.55 & 398.80 & 99.7 & 400.90 & 100.225 & 404.3 & 101.075 \\
\hline Mean & 399.820 & 99.955 & 399.80 & 99.95 & 400.54 & 100.135 & 400.77 & 100.192 \\
\hline STD & 1.616 & 0.404042 & 2.24 & 0.56097 & 1.15 & 0.287554 & 2.92 & 0.73106 \\
\hline RSD & 0.404 & 0.404224 & 0.56 & 0.561251 & 0.287167 & 0.287167 & 0.729663 & 0.72967 \\
\hline T-Test & 0.74 & & 0.68 & & 0.84 & & & \\
\hline \multirow[t]{2}{*}{ F-Test } & 1.39 & & 1.47 & & 1.14 & & & \\
\hline & \multicolumn{8}{|c|}{ Gaba 100 mg cap (NabiQasim) } \\
\hline Taken & Found & $\% \operatorname{Rec}$ & Found & $\% \operatorname{Rec}$ & Found & $\% \operatorname{Rec}$ & Found & $\%$ Rec \\
\hline 100 & 101.200 & 101.2 & 98.58 & 101.2 & 101.33 & 101.33 & 101.2 & 101.2 \\
\hline 100 & 99.800 & 99.8 & 99.64 & 99.8 & 99.66 & 99.66 & 98.96 & 98.96 \\
\hline 100 & 100.600 & 100.6 & 110.80 & 100.6 & 98.44 & 98.44 & 99.47 & 99.47 \\
\hline 100 & 100.700 & 100.7 & 100.33 & 100.7 & 101.30 & 101.3 & 100.22 & 100.22 \\
\hline 100 & 99.500 & 99.5 & 101.20 & 99.5 & 100.66 & 100.33 & 99.32 & 99.32 \\
\hline
\end{tabular}


Table 5 Determination of gabapentin in pharmaceuticals formulations by proposed (Continued)

\begin{tabular}{ccccccccc}
\hline Mean & 100.360 & 100.36 & 100.11 & 100.36 & 100.28 & 100.278 & 99.83 & 99.834 \\
STD & 0.695 & 0.694982 & 1.03 & 0.694982 & 1.23 & 1.230577 & 0.89 & 0.8919 \\
RSD & 0.692 & 0.692489 & 1.03 & 0.692489 & 1.227166 & 1.227166 & 0.892481 & 0.89248 \\
T-Test & 0.65 & & 0.88 & & 0.94 & & \\
F-Test & 1.37 & & 1.62 & & 1.08 & & \\
\hline
\end{tabular}

method (Abdellatef \& Khalil 2003) using the same samples. Similar accuracy and precision were observed for the calculated and theoretical values (95\% confidence) of the proposed and official methods as no remarkable difference was observed for the $\mathrm{t}$ and $\mathrm{F}$ tests. From Table 5 it is apparent that the present method can be followed for the analysis of these drugs in their single dosage forms. The recoveries in the range from 98.3 to $101.4 \%$ clearly showed no interference of any excipients of formulation.

\section{Spectroscopic studies \\ Infrared spectra}

The IR spectra of gabapentin+Nin Complex showed neither the expected doublet of primary $\mathrm{NH}_{2}$ in the region $3200-3400 \mathrm{~cm}^{-1}$ nor the usual carbonyl stretch of $\mathrm{COOH}$ near $1710 \mathrm{~cm}^{-1}$. Instead multiple peaks were observed in the region $2500-3000 \mathrm{~cm}^{-1}$ that can be attributed to ammonium ion $\left(\mathrm{NH}_{3}^{+}\right)$, the asymmetric and symmetric peaks of carboxylate ion were observed at 1600 and $1400 \mathrm{~cm}^{-1}$ coincide with the one observed in amino acids (Wright \& Vanderkooi 1997) and $\mathrm{NH}_{3}^{+}$ bending at $1550 \mathrm{~cm}^{-1}$ conclude that the gabapentin exists in zwitterionic form. Our studies match up to the already reported infrared absorptions of gabapentin (Chimatadar et al. 2007).

NIN produced two broad bands at 3300 and $3250 \mathrm{~cm}^{-1}$ and a $\mathrm{C}-\mathrm{O}$ stretching at $1061 \mathrm{~cm}^{-1}$ signify the presence of two $\mathrm{OH}$ groups. The carbonyl gave two peaks in the region 1660 to $1760 \mathrm{~cm}^{-1}$. Aromatic resonance appeared at $750 \mathrm{~cm}^{-1}$ (Arayne et al. 2008; Charles \& Pouchert 1989; Charles \& Pouchert 1981).

Primary amines to give Ruhemann's Purple complex with NIN (Arayne et al. 2008). The formation of the complex was evidenced by comparing the spectra of complex with parent reactant. Many of the functionalities of NIN and gabapentin were found absent which confirms the formation of complex. The doublet of

Table 6 Recovery of Gabapentin in presence of different excipient

\begin{tabular}{ccccccc}
\hline & Pyrro & Lactose & Talc & Mag Stea & Starch & HPMC \\
\hline Initial Rate & 99.46 & 99.39 & 100.26 & 99.87 & 101.2 & 98.96 \\
Rate Constant & 98.92 & 100.66 & 100.33 & 99.55 & 101.47 & 99.1 \\
Fixed Time & 100.43 & 99.24 & 101.27 & 98.92 & 99.37 & 100.84 \\
\hline
\end{tabular}

carbonyl in NIN changed significantly into one single sharp peak at $1680 \mathrm{~cm}^{-1}$ and the broad band of $\mathrm{O}-\mathrm{H}$ shifted to $3400 \mathrm{~cm}^{-1}$.

\section{Nuclear magnetic resonance spectra}

The ${ }^{1} \mathrm{H}$ NMR spectra of gabapentin showed two $-\mathrm{CH}_{2}$ peaks at $\Delta 2.443$ and $\Delta 2.873 \mathrm{ppm}$ and the cyclohexyl protons appeared in the region of $\Delta 1.365-1.585 \mathrm{ppm}$. The likely peak of $\mathrm{NH}_{2}$ near $\Delta 2$ ppm and that of carboxylic $\mathrm{OH}$ near $\Delta 11 \mathrm{ppm}$ were not observed but one peak of $\mathrm{NH} 3+$ at $4.849 \Delta \mathrm{ppm}$ was observed, may be as suggested earlier, due to zwitterion formation. Same is also reported in literature (Chimatadar et al. 2007). NIN exhibited two singlets at $\Delta 7.240$ and $\Delta 7.446 \mathrm{ppm}$ for the four protons of the aromatic group and a singlet at $\Delta 1.52 \mathrm{ppm}$ for two protons of the $\mathrm{OH}$ group. This coincides with the reported studies (Arayne et al. 2008; Charles \& Pouchert 1981). By studying the ${ }^{1} \mathrm{H}-\mathrm{NMR}$ spectrum of the gaba-NIN complex it was found that the $\mathrm{NH}_{2}$ protons completely diminished and the broad multiplet appearing between $\Delta 7.42$ and $\Delta 8.163 \mathrm{ppm}$ showing eight aromatic $\mathrm{CH}$ protons. A singlet at $\Delta$ $4.803 \mathrm{ppm}$ represents the enolic $\mathrm{OH}$ proton. The above results were found in accord with UV and IR spectra, confirming the proposed structure.

\section{Conclusion}

The data given above divulge that the proposed methods are easy, accurate and sensitive with good precision and accuracy. With these methods, one can do the analysis with pace at low cost without losing accuracy. The proposed methods can be used as alternative methods to the reported ones for the routine determination of gabapentin in pharmaceutical formulations. This encourages their successful use in routine analysis of these drugs in quality control laboratories.

\section{Competing interests}

The authors declare that they have no competing interests.

\section{Authors' contributions}

FAS designed, coordinated and carried out experiments the study. NS, NS and HS carried out experiments, FAS, NS, NS, HS and AZ drafted the manuscript. All authors read and approved the final manuscript. 


\section{Author details}

${ }^{1}$ Faculty of Pharmacy, Federal Urdu University Arts, Science and Technology, Karachi 75300, Pakistan. ${ }^{2}$ Department of Chemistry, University of Karachi, Karachi 75270, Pakistan. ${ }^{3}$ Research Institute of Pharmaceutical Sciences, Faculty of Pharmacy, University of Karachi, Karachi 75270, Pakistan. ${ }^{4}$ Department of Environmental Sciences, Federal Urdu University Arts, Science and Technology, Karachi 75300, Pakistan.

Received: 11 June 2013 Accepted: 26 September 2013 Published: 31 Oct 2013

\section{References}

Abdellatef HE, Khalil HM (2003) Colorimetric determination of gabapentin in pharmaceutical formulation. J Pharmaceut Biomed Anal 31:209-214

Abdulrahman SAM, Basavaiah K (2011) Sensitive and selective spectrophotometric determination of gabapentin in capsules using two nitrophenols as chromogenic agents. Int J Anal Chem 2011:1-9. Article ID 619310. doi:10.1155/2011/619310

Abdulrahman SAM, Basavaiah K (2012) Highly sensitive spectrophotometric method for the determination of gabapentin in capsules using sodium hypochloride. Turk J Pharm Sci 9:113-126

al-Zehouri J, al-Madi S, Belal F (2001) Arzneimittel-forsch 51:97

Arayne MS, Sultana N, Siddiqui FA, Mirza AZ, Zuberi MH (2008) Spectrophotometric techniques to determine tranexamic acid: Kinetic studies using ninhydrin and direct measuring using ferric chloride. J Mol Struc 889:475-480

Belal F, Abdine H, Al-Majed A, Khalil NY (2002) Spectrofluorimetric determination of vigabatrin and gabapentin in urine and dosage forms through derivatization with fluorescamine. J Pharm Biomed Anal 27:253-260

Benesi HA, Hidelbrand J (1949) A Spectrophotometric investigation of the Interaction of lodine with Aromatic Hydrocarbons. J Am Chem Soc 71:2703

Campins-Falco P, Sevillano-Cabza A, Gallo-Martinez L, Bosch-Reig F (1996) A comparison of various calibration techniques applied to the ninhydrincefoxitin determination. Anal Chim Acta 324:199

Chimatadar SA, Basavaraj T, Thabaj KA, Nandibewoor ST (2007) J Mol Catal A Chem 267(1-2):65-71

Chollet DF, Goumaz L, Juliano C, Anderegg G (2000) Fast isocratic high-performance liquid chromatographic assay method for the simultaneous determination of gabapentin and vigabatrin in human serum. J Chromatogr B 746:311-314

Friedman M (2004) Applications of the ninhydrin reaction for analysis of amino acids, peptides, and proteins to agricultural and biomedical sciences. Agric Food Chem 52:385-406

Goldlust A, Su TZ, Welty DF, Taylor CP, Oxender DL (1995) Effects of anticonvulsant drug gabapentin on the enzymes in metabolic pathways of glutamate and GABA. Epilepsy Res 22:1-11

Görög S (1995) Ultraviolet-Visible Spectrophotometry in Pharmaceutical Analysis. CRC Press, New York, p 318

Hassan EM, Belal F, Al-Deeb OA, Khalil NY (2001) Spectrofluorimetric determination of vigabatrin and gabapentin in dosage forms and spiked plasma samples through derivatization with 4-chloro-7-nitrobenzo-2-oxa-1,3diazole. J AOAC Int 84:1017-1024

Hegde RN, Kumara Swamy BE, Shetti NP, Nandibewoor ST (2009) Electrooxidation and determination of gabapentin at gold electrode. J Electroanal Chem 635:51-57

ICH Topic Q2(R1) (2005) Validation of analytical procedures: text and methodology. Current step 4 version parent guideline dated 27 October 1994 (Complementary Guideline on Methodology dated 6 November 1996 incorporated in November 2005)

Ifa DR, Falci M, Moraes ME, Bezerra FA, Moraes MO, de Nucci G, (2001) Gabapentin quantification in human plasma by high-performance liquid chromatography coupled to electrospray tandem mass spectrometry. Application to bioequivalence study. J Mass Spectro 36:188-194

Jalali F, Arkan E, Bahrami G (2007) Preparation of a gabapentin potentiometric sensor and its application to pharmaceutical analysis. Sens Actuat B: Chem 127:304-309

Jia S, Lee HS, Choi MJ, Hyun Sung S, Sang BH, et al. (2012) Non-derivatization method for the determination of gabapentin in pharmaceutical formulations, Rat serum and Rat urine using high performance liquid chromatography coupled with charged aerosol detection. Curr Anal Chem 8:159-167
Jiang Q, Li S (1999) Rapid high-performance liquid chromatographic determination of serum gabapentin. J Chromatogr B 727:119-123

Kushnir MM, Crossett J, Brown PI, Urry FM (1999) Analysis of gabapentin in serum and plasma by solid-phase extraction and gas chromatography-mass spectrometry for therapeutic drug monitoring. J Anal Toxicol 23:1-6

Lin FM, Kou HS, Wu SM, Chen SH, Wu HL (2004) Capillary electrophoresis analysis of gabapentin and vigabatrin in pharmaceutical preparations as ofloxacin derivatives. Anal Chim Acta 523:9-14

Manera M, Miro M, Ribeiro MF, Estela JM, Cerda V, et al. (2009) Rapid chemiluminometric determination of gabapentin in pharmaceutical formulations exploiting pulsed-flow analysis. Luminescence 24:10-14

Martin AN, Swarbrick J, Cammarata A (1969) Physical Pharmacy, 3rd edition. Lee \& Febiger, Philadelphia, PA, p 344

Molnar-Perl I, Pinter-Szakacs M (1989) Spectrophotometric determination of tryptophan in intact proteins by the acid ninhydrin method. Anal Biochem 177:16-19

Nobrega Jde A, Fatibello-Filho O, Vieira Ida C (1994) Flow injection spectrophotometric determination of aspartame in dietary products. Analyst 119:2101-2104

Ouellet D, Bockbrader HN, Wesche DL, Shapiro DY, Garofalo E (2001) Population pharmacokinetics of gabapentin in infants and children. Epilepsy Res 47:229241

Patel B, Patel J, Singh H, Patel B (2011) Extractive spectrophotometric methods for the determination of gabapentin in pharmaceutical dosage forms. Int J Pharma Sci Drug Res 3:197-201

Pouchert JC (1981) The Aldrich library of infrared spectra, Volume 2, 2nd edition. Aldrich Chemical Company, University of California

Pouchert JC (1983) The Aldrich library of NMR Spectra, 2 Volume Set, 2nd edition. Bookseller: Mountainview Books, Hopeland, PA, USA

Rada P, Tucci S, Perez J, Teneud L, Chuecos S, Hernandez L (1998) In vivo monitoring of gabapentin in rats: a microdialysis study coupled to capillary electrophoresis and laser-induced fluorescence detection. Electrophoresis 19:2976-2980

Rahman N, Azmi SNH (2001a) Spectrophotometric method for the determination of amlodipine besylate with ninhydrin in drug formulations. IL Farmaco 56:731-735

Rahman N, Azmi SN (2001b) Farmacokinetics 56:731-735

Ratnaraj N, Patsalos PN (1998) A high-performance liquid chromatography micromethod for the simultaneous determination of vigabatrin and gabapentin in serum. Ther Drug Monit 20:430-434

Ribeiro MF, Santos JL, Lima JL (2007) Piezoelectric pumping in flow analysis: application to the spectrophotometric determination of gabapentin. Ana Chim Acta 600:14-20

Rose J (1964) Adv Physico-Chem Exp. Pittman, London, p 54

Siddiqui FA, Arayne MS, Sultana N, Qureshi F, Mirza AZ, et al. (2010) Spectrophotometric determination of gabapentin in pharmaceutical formulations using ninhydrin and pi-acceptors. Eur J Med Chem 45:27612767

Tang PH, Miles MV, Glauser TA, DeGrauw T (1999) Automated microanalysis of gabapentin in human serum by high-performance liquid chromatography with fluorometric detection. J Chromatogr B 727:125-129

Van Lentea F, Gatautis V (1998) Cost-efficient use of gas chromatography-mass spectrometry: a "piggyback" method for analysis of gabapentin. Clin Chem 44:2044-2045

Wad N, Kramer G (1998) Sensitive high-performance liquid chromatographic method with fluorometric detection for the simultaneous determination of gabapentin and vigabatrin in serum and uein. J Chromatogr B 705:154-158

Wright WW, Vanderkooi JM (1997) Use of IR absorption of the carboxyl group of amino acids and their metabolites to determine $\mathrm{pKs}$, to study proteins, and to monitor enzymatic activity. Biospectroscopy 3:457-467

\subsection{6/2093-3371-4-17}

Cite this article as: Siddiqui et al:: Kinetic and Thermodynamic Spectrophotometric Technique to Estimate Gabapentin in

Pharmaceutical Formulations using Ninhydrin. Journal of Analytical Science and Technology 2013, 4:17 